\title{
High-Performance Work Systems In Small And Micro Business: Impact on employee organizational citizenship behavior
}

\author{
Zichen Wang ${ }^{1, \mathrm{a}}$,Tanapol Kortana ${ }^{2, \mathrm{~b}}$ \\ ${ }^{1}$ College of Innovation and Management Suan Sunandha Rajabhat University Bangkok, Thailand \\ ${ }^{2}$ College of Innovation and Management Suan Sunandha Rajabhat University Bangkok, Thailand
}

\begin{abstract}
Due to the intensified market competition, companies must seek lower-cost and efficient corporate management methods in order to sustainably develop. The concept of high performance work system (HPWS) came into being in this situation. The main purpose of this research is to explore the relationship between high-performance work systems and employee well-being and organizational citizenship behavior. This research takes China's small and medium-sized enterprises(SMEs) as the research objects of the survey. After analysis using SmartPLS, it is found that the high-performance work system will have a positive and significant impact on well-being and employee citizenship behavior. At the same time, wellbeing plays a mediator variable in the relationship between the high-performance work system and employee citizenship behavior.
\end{abstract}

\section{Introduction}

With the development of human resource theory and the proposal of strategic human resource management theory, more and more scholars have begun to study its relationship with organizational performance from the perspective of "High Performance Work System (HPWS)". Previous studies by scholars pointed out that high performance work system (HPWS) can effectively improve employee satisfaction and reduce enterprise operating costs [1], [2]. Another point worth noting is that employees' subjective well-being and emotions at work are closely related to corporate competitiveness. Many companies have begun to attach importance to employees' feelings at work in order to attract outstanding talents to work in the company while retaining existing employees. [3]. Past studies have also confirmed that overwork will increase employees' mental burnout and reduce their happiness and job satisfaction, while major events such as job promotion, salary increase, and improvement of the office environment will increase employees' well-being. It has a huge impact on personal happiness [4]. Previous studies have shown that the higher the employee's happiness, the better the work performance, and the increase in efficiency and productivity [5].

This research bridges the gap between the theory, concept, and empirical demonstration of the impact of high-performance work systems on increasing employees' organizational citizenship behavior. The research question is thus formulated to answer: (1) How does a high-performance work system affect employees' organizational citizenship behavior? (2) What impact does the high-performance work system have on employees' well-being? (3) What impact does employee well-being have on employee organizational citizenship behavior?

\section{Literature Review}

\subsection{High Performance Work System}

Strategic human resource management refers to the human resource management strategy that enterprises need to adopt in order to achieve their predetermined goals when facing the internal and external environment of the enterprise [6], [7]. High performance work system (HPWS) is a series of policies and activities that can make the company highly consistent and ensure that human resources serve the corporate strategic goals [8]. A highperformance work system can improve the skills, information, and motivation required by employees for work, and can therefore enhance the competitiveness of the organization [9]. High-performance human resources measures can effectively motivate employees so that they can perform better at work, thereby improving organizational performance [10].

\subsection{Well-Bing}

Well-being can be divided into two dimensions: emotion and cognition. Therefore, happiness includes personal happiness in life and positive and negative emotions from psychology and society [11], [12]. Well-being is a relative concept, which comes from personal values, past and present life experiences, or a relative comparison of one's

às62484945010@ssru.ac.th btanapol.ko@ssru.ac.th 
own life experience and state with one's or others' lives [13], [14].

\subsection{Organizational Citizenship Behavior}

The concept of organizational citizenship behavior is derived from the concept of organizational citizenship. Organizational citizenship refers to the exchange relationship between employees and the organization, that is, the organization agrees to some rights of the employees, and the employees fulfill their obligations to the organization [15]. Organizational citizenship behavior is a spontaneous behavior, which means that even if the organization does not require it, some employees will still engage in behaviors that are beneficial to the organization or colleagues, and this behavior will have a positive impact on organizational effectiveness [16]. Organizational citizenship behavior is a behavior in which employees voluntarily support overall interests rather than private interests. This behavior exceeds the company's requirements for employee positions [17].

\subsection{Hypotheses}

Based on the research purpose of this research and literature review, four hypotheses are proposed. The four hypotheses are developed as follows:

H1: High performance work system has a significant influence on well-being.

H2: High performance work system has a significant influence on organization citizenship behavior.

H3: Well-being has a significant influence on organization citizenship behavior.

H4: Well-being mediates the relationship between high performance work system and organization citizenship behavior.

\section{Methodolgy}

This operational definition of the high-performance work system as the extent to which the organization implements selection, training and development and performance management measures in order to enhance the organization's current and potential employees' knowledge, technology, and capabilities. The highperformance work system contains three dimensions, and a total of eleven questions are used to measure: (1) selection; (2) training and development; (3) performance management.

The operational definition of well-being is the overall assessment of an individual's satisfaction with his current life and his own positive emotions. The operational definition of organizational citizenship behavior refers to the spontaneous behavior of employees, which will bring benefits to the organization.

This study uses electronic questionnaires to collect data from small- and medium-sized enterprises in Thailand, using a conceptual sampling method, and contacting them by phone or email to confirm their willingness to cooperate. A total of 200 questionnaires were distributed from June 1, 2020 to July 1, 2020. After deleting invalid questionnaires with a response time of less than one minute, a total of 99 valid questionnaires were returned, with an effective recovery rate of $49.5 \%$.

\section{Research Finding}

\subsection{Measurement Model}

Table 1 shows that all item loadings exceeded the recommended value of 0.6 [18]. The results indicate that Cronbach's alpha coefficients of all items ranging from 0.631 to 0.824 were more significant than the proposed value of 0.6 [19]. Additionally, Table 1 shows the result of testing construct reliability all the $\mathrm{CR}$ values of all the items ranging from 0.802 to 0.888 were found to be higher than the proposed value of 0.7 [20], [21]. The result of the average variance extracted ranging from 0.576 to 0.726 , which reflects the overall amount of variance in the indicators accounted for by the latent construct, exceeded the recommended value of 0.5 [22]. In summary, the measurement scale of this study has convergence validity. Table 2 shows that the square root (diagonal value) of the AVE for each structure is greater than the corresponding correlation coefficient that points to the appropriate discriminant validity [23]. 


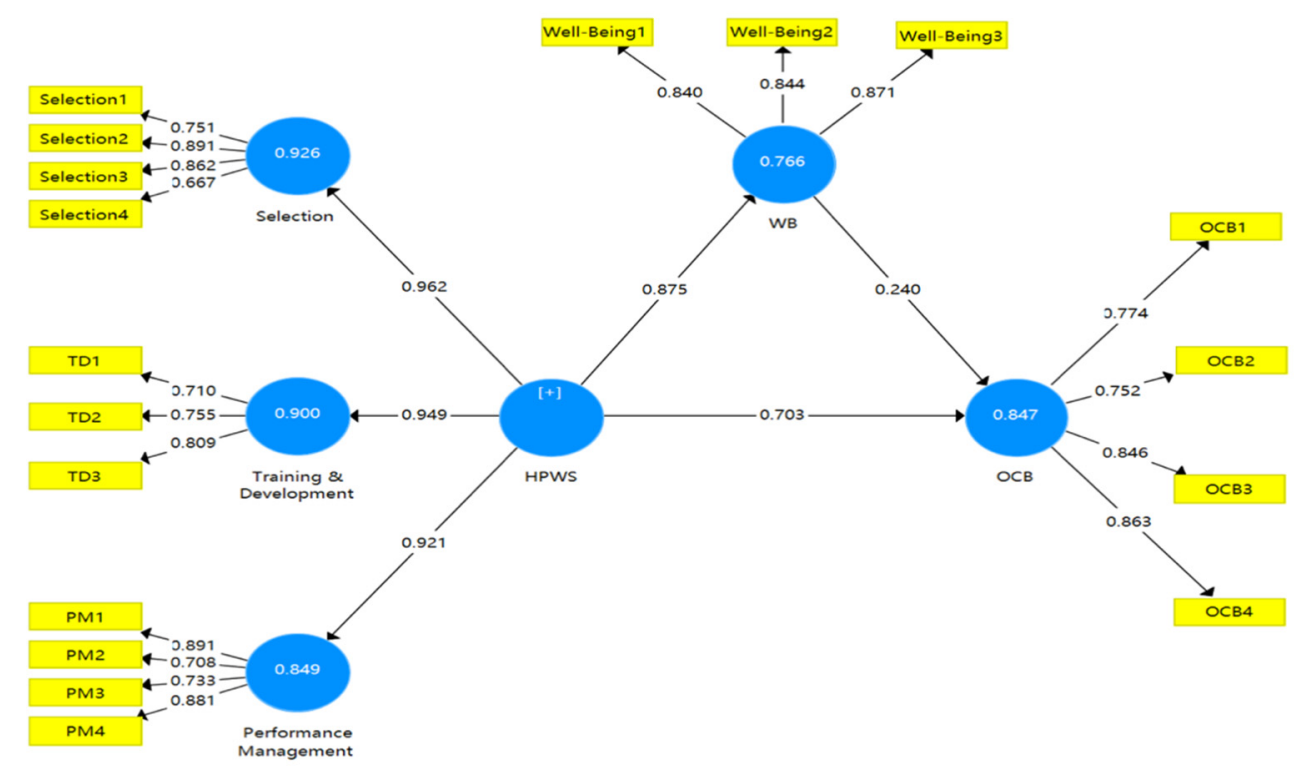

Fig 1. Structural model assessment

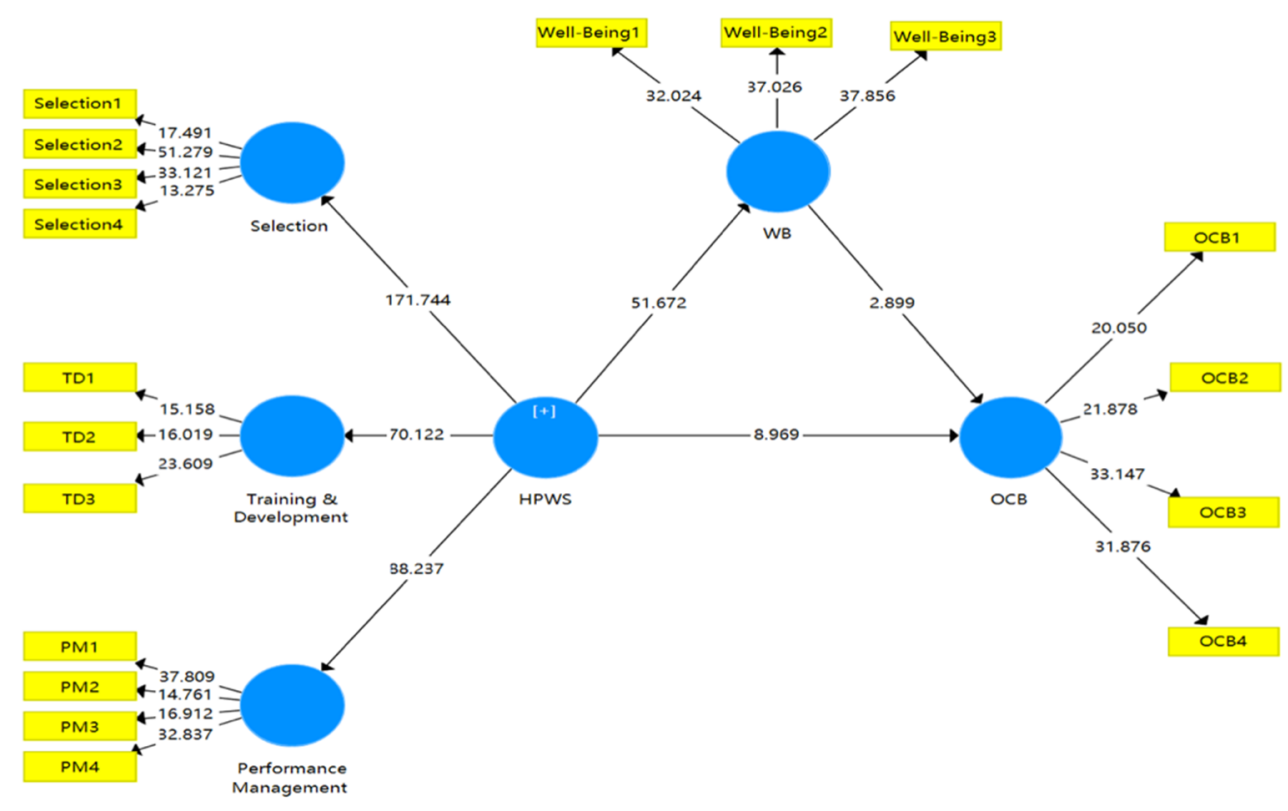

Fig 2. Effect size

Table1. Validity and reliability for constructs.

\begin{tabular}{cccccc}
\hline Constructs & Items & Loadings & $\begin{array}{c}\text { Cronbach's } \\
\text { alpha }\end{array}$ & CR & AVE \\
\hline OCB & OCB1 & 0.774 & 0.824 & 0.884 & 0.656 \\
& OCB2 & 0.752 & & & \\
& OCB3 & 0.846 & & & \\
\hline OCB4 & 0.863 & & 0.881 & 0.652 \\
& PM1 & 0.891 & 0.818 & & \\
& PM2 & 0.708 & & & \\
\hline Selection & PM3 & 0.733 & & & \\
& PM4 & 0.880 & & & \\
& Selection1 & 0.751 & 0.804 & 0.874 & 0.636 \\
& Selection2 & 0.891 & & & \\
& Selection3 & 0.862 & & & \\
\hline TD & Selection4 & 0.801 & & & \\
& TD1 & 0.709 & 0.631 & 0.802 & 0.576 \\
& TD2 & 0.755 & & & \\
\hline \multirow{2}{*}{ Well-Being } & Well-Being1 & 0.809 & & & \\
& Well-Being2 & 0.844 & 0.811 & 0.888 & 0.726 \\
& Well-Being3 & 0.871 & & & \\
\hline
\end{tabular}

\subsection{Structural Model}

The structural model assessment, as shown in Figure 1, 2, reveals the results of hypothesis tests. This study examines the relationship between variables.

High-performance work systems (HPWS) positively and significantly affected employee well-being $(\beta=0.875$; $\mathrm{t}=51.672 ; \mathrm{p}<0.001)$, organization citizenship behavior $(\beta=0.703 ; t=8.969 ; p<0.001)$. In addition, employee well-being also positively and significantly affected organization citizenship behavior $(\beta=0.240 ; t=2.899 ; p$ $<0.001)$. Thus hypothesis 1 , hypothesis 2 and hypothesis 3 were all supported. At the same time, well-being mediates the relationship between high-performance 
work systems and employee citizenship behavior $(\beta=$ $0.210 ; \mathrm{p}<0.004)$.

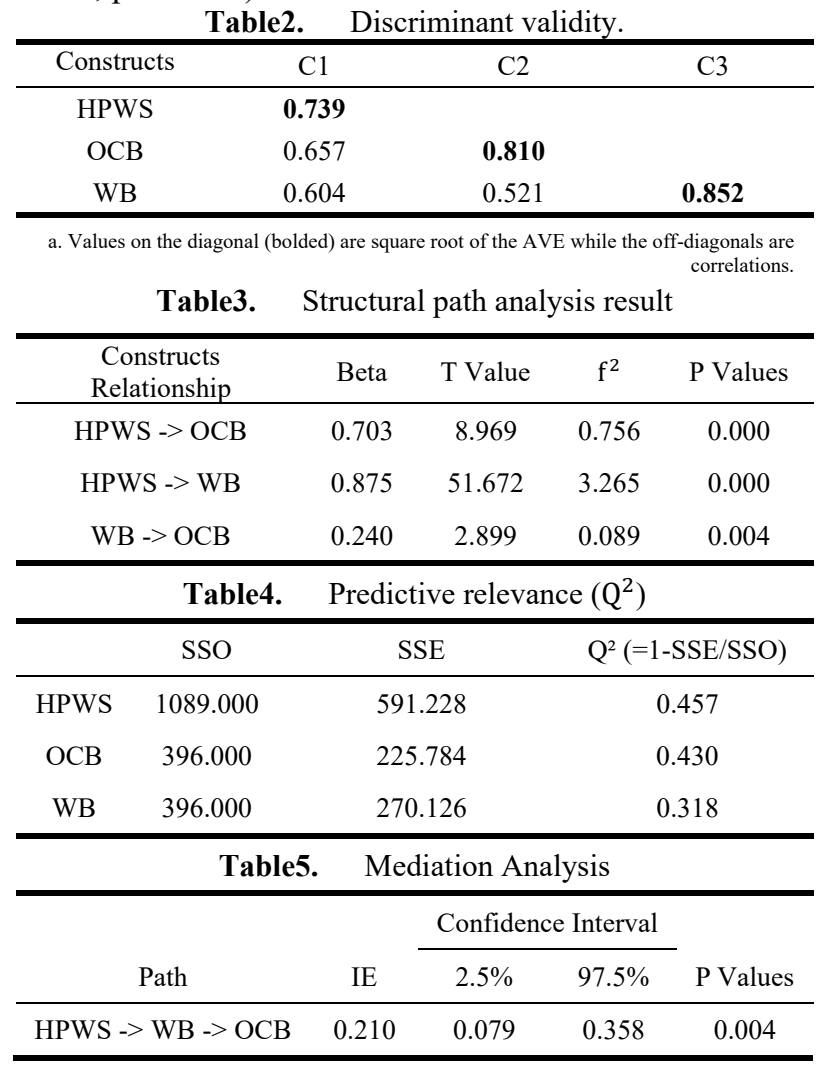

\section{Conclusion}

The main purpose of this research is to explore the relationship between the implementation of the highperformance work system in the organization and the well-being and organizational citizenship behavior of employees. The research results show that the highperformance work system will have a positive and significant impact on the well-being of employees. That is to say, the higher the degree of implementation of the high-performance work system by the enterprise, the higher the employee's satisfaction in the work process. At the same time, the use of a high-performance work system will also make it easier for employees to produce employee citizenship behavior and to voluntarily do things that are beneficial to the organization.

Based on the results of data analysis, this research provides specific management implications and relevant suggestions for reference in the work of the practical community. This research suggests that companies can use the implementation of high-performance work systems to make employees feel well-being in the work process, which in turn encourages employees to exhibit a higher degree of organizational citizenship behavior. This will improve the overall performance of the organization, which in turn is conducive to the sustainable operation of the company.

Since this research mainly explores the relationship between employee well-being, high-performance work systems, and organizational citizenship behavior, this research does not discuss the possible moderating effects of these three variables. Therefore, this study suggests that follow-up researchers can join the moderate variable to conduct research so that the impact mechanism of the high-performance work system on employee citizenship behavior is more complete.

\section{References}

1. Harmon, J., Scotti, D. J., Behson, S., Farias, G., Petzel, R., Neuman, J. H., \& Keashly, L. (2003). Effects of high-involvement work systems on employee satisfaction and service costs in veterans healthcare. Journal of Healthcare Management, 48(6), 393-406.

2. Zhang, M., Di Fan, D., \& Zhu, C. J. (2014). Highperformance work systems, corporate social performance and employee outcomes: Exploring the missing links. Journal of Business Ethics, 120(3), 423-435.

3. Alfes, K., Shantz, A. D., Truss, C., \& Soane, E. C. (2013). The link between perceived human resource management practices, engagement and employee behaviour: a moderated mediation model. The international Journal of Human Resource Management, 24(2), 330-351.

4. Taris, T. W., \& Schreurs, P. J. (2009). Well-being and organizational performance: An organizational-level test of the happy-productive worker hypothesis. Work \& Stress, 23(2), 120-136.

5. Robertson, I. T., Cooper, C. L., Sarkar, M., \& Curran, T. (2015). Resilience training in the workplace from 2003 to 2014: A systematic review. Journal of occupational and Organizational Psychology, 88(3), 533-562.

6. Lepak, D. P., \& Snell, S. A. (1999). The human resource architecture: Toward a theory of human capital allocation and development. Academy of Management Review, 24(1), 31-48.

7. Ringle, C. M., Sarstedt, M., Mitchell, R., \& Gudergan, S. P. (2020). Partial least squares structural equation modeling in HRM research. The International Journal of Human Resource Management, 31(12), 1617-1643.

8. Danvila-del-Valle, I., Estévez-Mendoza, C., \& Lara, F. J. (2019). Human resources training: A bibliometric analysis. Journal of Business Research, 101, 627-636.

9. Nadeem, K., Riaz, A., \& Danish, R. Q. (2019). Influence of high-performance work system on employee service performance and OCB: the mediating role of resilience. Journal of Global Entrepreneurship Research, 9(1), 1-13.

10. Jiang, K., Hu, J. I. A., Liu, S., \& Lepak, D. P. (2017). Understanding employees' perceptions of human resource practices: Effects of demographic dissimilarity to managers and coworkers. Human Resource Management, 56(1), 69-91.

11. HajiHassani, S. (2019). A Structural Model to Predict Subjective Well-Being based on Educational, Social, Emotional, Physical, and Security Climate of Schools 
through Mediation of Emotion Regulation. Quarterly Journal of Family and Research, 16(3), 7-28.

12. Diener, E., \& Tay, L. (2017). A scientific review of the remarkable benefits of happiness for successful and healthy living. Happiness, 90-117.

13. Schulte, P., \& Vainio, H. (2010). Well-being at workoverview and Perspective. Scandinavian Journal of Work, Environment \& Health, 36(5), 422-429.

14. Schulte, P. A., Guerin, R. J., Schill, A. L., Bhattacharya, A., Cunningham, T. R., Pandalai, S. P., ... \& Stephenson, C. M. (2015). Considerations for incorporating "well-being" in public policy for workers and workplaces. American Journal of Public Health, 105(8), 31-44.

15. Katz, D., \& Kahn, R. L. (1978). The social psychology of organizations. New York: Wiley.

16. Bateman, T. S., \& Organ, D. W. (1983). Job satisfaction and the good soldier: The relationship between affect and employee "citizenship". Academy of Management Journal, 26(4), 587-595.

17. Hughes, M., Rigtering, J. C., Covin, J. G., Bouncken, R. B., \& Kraus, S. (2018). Innovative behaviour, trust and perceived workplace performance. British Journal of Management, 29(4), 750-768.

18. Chin, W. W., Peterson, R. A., \& Brown, S. P. (2008). Structural equation modeling in marketing: Some practical reminders. Journal of Marketing Theory and Practice, 16(4), 287-298.

19. Taber, K. S. (2018). The use of Cronbach's alpha when developing and reporting research instruments in science education. Research in Science Education, 48(6), 1273-1296.

20. Werts, C. E., Linn, R. L., \& Jöreskog, K. G. (1974). Intraclass reliability estimates: Testing structural assumptions. Educational and Psychological Measurement, 34(1), 25-33.

21. Urbach, N., \& Ahlemann, F. (2010). Structural equation modeling in information systems research using partial least squares. Journal of Information Technology Theory and Application, 11(2), 5-40.

22. Hair, J. F., Ringle, C. M., \& Sarstedt, M. (2013). Partial least squares structural equation modeling: Rigorous applications, better results and higher acceptance. Long range planning, 46(1), 1-12.

23. Fornell, C., \& Larker, D. (1981). Structural equation modeling and regression: guidelines for research practice. Journal of Marketing Research, 18(1), 3950. 